\title{
A comparison of tactile and visual concept learning'
}

AARON WOLFGANG, Behavioral Science Laboratory, Radiation Therapy Section, Walter Reed General Hospital; Walter Reed Army Institute of Research, Washington, D. C. 20012

A task to study concept learning at different complexity levels through the tactile sense only was devised. Results from three experiments indicated that when Ss classified objects tactually concept learning was most difficult when size, texture, and thickness were relevant and easiest when the relevant dimensions were form or dot. There was no significant difference in errors and time to solution between visual and tactile concept learning.

How important is the tactile sense in classifying information? Although the tactile sense is used in daily activities for decision making from childhood to adulthood, there is little or no systematic training given in utilizing this sensory modality except for learning such special skills as playing musical instruments or typewriting. Insight can be gained into the importance of tactile cues from the blind or blind-deaf who must depend heavily on tactile feedback in dealing with the environment. Although all sensory modalities are utilized in gathering and classifying information, most concept identification investigators and theorists have studied conceptual behavior through the visual modality only. There have been only a few Es who have attempted to compare efficiency of different sensory modalities as audio-visual in conecpt identification (Bulgarella \& Archer, 1962; Haygood, 1965; Lordahl, 1961). However, research comparing tactile and visual concept identification at different complexity levels is totally lacking.

The purpose of the present series of studies was threefold: (1) to establish learning rates for different relevant dimensions where only tactile cues were available; (2) to compare learning rates between visual and tactile concept identification across several relevant dimensions; and (3) to compare visual and tactile learning at different levels of concept complexity.

In Experiments 1, 2, and 3 there were 48, 48, and $96 \mathrm{Ss}$, respectively. All Ss were military duty personnel assigned to Walter Reed Army Medical Center. Their overall mean age was 25.50 years (range: 19-52) and mean education was 12.56 years (range: 8-18).

The subjects' task in solving a two-choice concept identification problem was to categorize a series of geometric figures in accordance with one relevant binary stimulus dimension. For instance, if texture of the object was the relevant dimension, then if $S$ pushed Button $A$ when all objects were smooth and Button B when rough he would be correct. However, if Ss responded to the irrelevant dimensions (e.g., thickness: thin or thick) then Ss would be correct only at the chance level.

The tactile objects were presented manually. These objects were individually weighted with lead pellets so they were of equal weight when the size and thickness differed. The plastic objects were varied along the following dimensions: shape (triangle-square); size (4-2 in. blocks); thickness (5/1611/16 in.); texture (rough-smooth); dot-no dot on object; serrated-smooth edges. Also, there were two identical interconnected black aluminum panel boxes $(10 \times 5 \times 3$ in.) with two response buttons identified by the letters $A$ and $B$, and two feedback lights. When S pressed A button E's panel lit up indicating S's choice of response and then the $E$ using a planned program of feedback pressed a button which lit one of the feedback lights on the S's panel box for approximately $I$ sec indicating to $S$ the correctness of his response.
After Ss were seated at a desk they were given instructions concerning the task, significance of the response keys and feedback lights, and were told to place their hands into a black cardboard box, the openings of which were covered by black felt. A black opaque rubber screen tacked to a wooden structure $27 \mathrm{in}$. high was placed between $S$ and $E$ to prevent $S$ from viewing the stimulus objects, E's panel box, and program of feedback. The E placed each object in S's hands and S was told to feel and touch each of the objects for as long as he wished and to classify them into one of two categories by pressing Button A or B on his panel box. Ss were told to inform the $\mathrm{E}$ when they knew the solution to the problem, otherwise criterion to solution was 16 consecutive correct responses. If criterion was not reached, then Ss were given a maximum of $20 \mathrm{~min}$ to reach solution.

On the visual task, geometric figures appeared in a box and were presented manually at S's eye level on $3 \times 5$ in. index cards. $S$ and $E$ had identical sloping panels with two response keys and two feedback lights that were attached to a black wooden frame $20 \mathrm{in}$. high and $20 \mathrm{in}$. wide to prevent Ss from viewing $E$ 's panel board and program. Instructions and criterion to solution for the visual task were identical to those for the tactile task.

In Experiment 1 Ss were divided into six independent treatment groups. Each group worked on a different relevant dimension for the tactile task (shape, size, thickness, texture, dot-no dot, and serrated-smooth edges). In each problem there was always one relevant dimension accompanied by four irrelevant dimensions.

Subjects in Experiment 2 participated in a 3 by 2 factorial design which included two modes of stimulus presentation (visual-tactile) and three problem types (shape, size, and dot-no dot as relevant dimensions).

Lastly, in Experiment 3 Ss participated in a 3 by 2 by 2 factorial design that included three levels of task complexity (3, 4 , or 5 irrelevant dimensions); two modes of stimulus presentation (visual-tactile) and two problem types (size and shape as relevant dimensions).

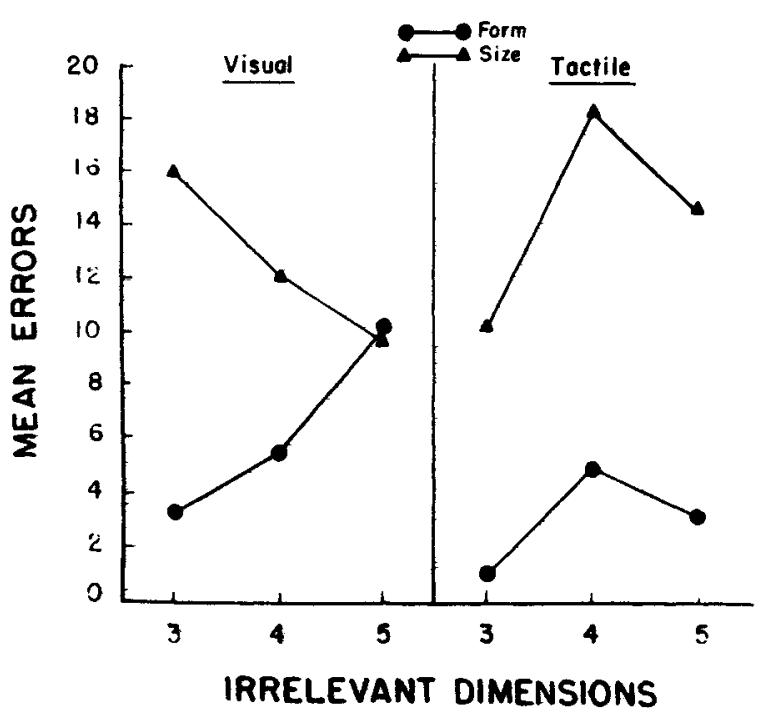

Fig. 1. Mean errors as a function of number of imelevant dimensions, type of relevant information and mode of stimulus presentation. 
Table 1

Mean Errors and Mean Time on the Tactile Task as a Function of Relevant Dimensions

\begin{tabular}{lllllll}
\hline Means & \multicolumn{6}{c}{ Relevant Dimensions } \\
\cline { 2 - 5 } & Form & Size & Dot & Texture & Thickness & $\begin{array}{c}\text { Serrated } \\
\text { Edges }\end{array}$ \\
\hline $\begin{array}{l}\text { Mean } \\
\text { Errors }\end{array}$ & 5.12 & 18.37 & 3.12 & 14.25 & 16.87 & 9.37 \\
$\begin{array}{l}\text { Mean } \\
\text { Time } \\
\text { (min) }\end{array}$ & 6.00 & 12.62 & 3.62 & 12.25 & 12.87 & 7.12 \\
\hline
\end{tabular}

\section{RESULTS AND DISCUSSION}

The main dependent variables were errors and time in minutes to criterion. The data in Experiment 1 indicated that both error and time scores were similar. Analysis of variance showed that the main effect for time to solution was significant $(F=2.85, \mathrm{df}=5 / 42, \mathrm{p}<.05)$ but insignificant for errors $(F=1.95, \mathrm{df}=5 / 42, \mathrm{p}>.05)$. Table 1 shows that tactile concept identification was easiest for protruding dots and shape and most difficult for size, thickness, and texture. That form was a more salient dimension than texture was consistent with the findings of Brown \& Smith (1967).

Results further showed that when protruding dot, serrated edges, and shape were relevant dimensions all Ss attained solution whereas only $50 \%$ reached criterion when tex ture was relevant and $62 \%$ when size and thickness were the relevant dimensions.

Although all objects large or small were weighted the same and Ss were told to disregard weight because it was used as an example for problem solution, two-thirds of the Ss used weight as a cue in attaining solution when size was the relevant dimension. These Ss classified large objects as light and small as heavy. This was probably due to the weight being distributed over a larger surface area for large objects and giving the sensation of lightness whereas for small objects weight was concentrated in a smaller area giving the sensation of heaviness.

The analysis of variance in Experiment 2 showed that the main effect of problems was significant for errors $(F=6.53$, $\mathrm{df}=2 / 42, \mathrm{p}<.005)$ and time $(\mathrm{F}=8.90, \mathrm{df}=2 / 42, \mathrm{p}<.001)$ but mode of stimulus presentation and the interaction were insignificant $(p>.05)$. Subsequent analysis for problems with Duncan's test showed that Ss made fewer errors when dot was relevant than size $(p<.005)$ and fewer errors when form was relevant compared to size $(\mathrm{p}<.05)$. Duncan's test for the time data yielded essentially the same results. Thus, size was the most difficult concept to identify whether presented visually or tactually.

Results in Experiment 3 showed that only the problems main effects were significant for time $(F=24.03, \mathrm{df}=1 / 84$, $\mathrm{p}<.001)$ and errors $(\mathrm{F}=37.10, \mathrm{df}=1 / 84, \mathrm{p}<.001)$. All other variables and interactions were insignificant $(p>.05)$. The significant problems main effect indicated that Ss made fewer errors and took less time to reach solution when form was relevant than size.

A Duncan's test showed, as does Fig. 1, that Ss on the tactile task made significantly fewer errors when form was the relevant dimension than size at all complexity levels, three $(p<.05)$, four $(p<.01)$ and five irrelevant dimensions $(p<.01)$ whereas on the visual task it was only on the simplest problem that Ss made significantly fewer errors on form concepts than size $(p<.05)$ indicating that only on the tactile test was form consistently a more salient dimension than size.

In future experiments a more direct comparison could be made between visual and tactile concept identification by using plastic objects for the visual task instead of presenting the stimulus figures on cards.

\section{REFERENCES}

BROWN, Z., \& SMITH, J. Tactual-kinesthetic discrimination shifts in retarded children. Journal of Experimental Child Psychology, 1967, 5, 455-462.

BULGARELLA, R. G., \& ARCHER, E. J. Concept identification of auditory stimuli as a function of amount of relevant and irrelevant information. Journal of Experimental Psychology, 1962, 63, 254-257.

HAYGOOD, D. H. Audio-visual concept formation. Journal of Educational Psychology, 1965, 56, 126-132.

LORDAHL, D. S. Concept identification using simultaneous auditory and visual signals. Journal of Experimental Psychology, 1961, 62, 283-290.

\section{NOTE}

1. This research was supported in part by the Defense Atomic Support Agency, RMD 1.153. 